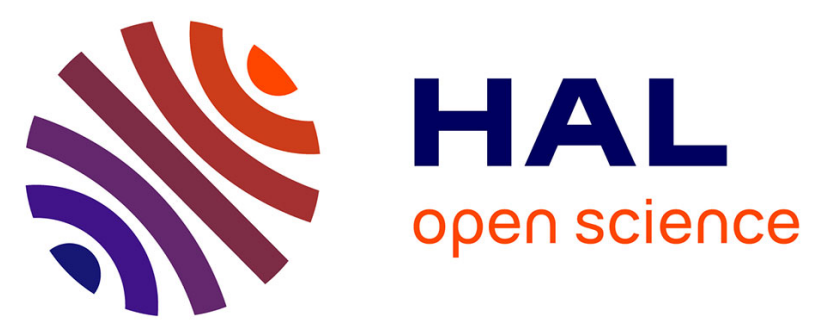

\title{
Application of "GaoFen-1" Satellite Data and "Micro-UAV" Data in Remote Sensing Monitoring in Winter Wheat-Illustrated by a Case of Jizhou in Hebei Province
}

\author{
Yuechen Liu, Weijie Jiao, Haijun Wang, Xue Han
}

\section{To cite this version:}

Yuechen Liu, Weijie Jiao, Haijun Wang, Xue Han. Application of "GaoFen-1" Satellite Data and "Micro-UAV" Data in Remote Sensing Monitoring in Winter Wheat-Illustrated by a Case of Jizhou in Hebei Province. 10th International Conference on Computer and Computing Technologies in Agriculture (CCTA), Oct 2016, Dongying, China. pp.20-29, 10.1007/978-3-030-06155-5_3 . hal-02179988

\section{HAL Id: hal-02179988 \\ https://inria.hal.science/hal-02179988}

Submitted on 12 Jul 2019

HAL is a multi-disciplinary open access archive for the deposit and dissemination of scientific research documents, whether they are published or not. The documents may come from teaching and research institutions in France or abroad, or from public or private research centers.
L'archive ouverte pluridisciplinaire HAL, est destinée au dépôt et à la diffusion de documents scientifiques de niveau recherche, publiés ou non, émanant des établissements d'enseignement et de recherche français ou étrangers, des laboratoires publics ou privés. 


\title{
Application of "GaoFen-1"Satellite Data and"Micro-UAV" Data in Remote Sensing Monitorimg in Winter Wheat-Illustrated By A Case of Jizhou in Hebei Province
}

\author{
Yuechen Liu, Weijie Jiao ${ }^{(\bowtie)}$, Haijun Wang, Xue Han \\ (Key Laboratory of Cultivated Land Use, Ministry of Agriculture, P. R. China / \\ Chinese Academy of Agricultural Engineering Planning \& Design, Beijing, 100125) \\ liuyuechen@agri.gov.cn
}

\begin{abstract}
This research utilized "GaoFen-1" $2 \mathrm{~m}$ panchromatic, $8 \mathrm{~m}$ and $16 \mathrm{~m}$ multispectral satellite data to monitor the planting area of winter wheat. Calculate the correction coefficient by the results of planting area of winter wheat gotten from "GaoFen-1" 16 m multispectral satellite data and micro unmanned aerial vehicle data. Correct the area extraction result of "GaoFen-1" $16 \mathrm{~m}$ multispectral satellite data and verify the accuracy of the results got from fusion data of $2 \mathrm{~m}$ resolution and $8 \mathrm{~m}$ resolution of "GaoFen-1" by micro unmanned aerial vehicle data. Then compare with the area extraction results, extracted from the data of fusion data of $2 \mathrm{~m}$ resolution and $8 \mathrm{~m}$ resolution of "GaoFen-1" and the corrected $16 \mathrm{~m}$ multispectral satellite data, in Jizhou. The study result show that the corrected extraction result of planting area of winter wheat, from "GaoFen-1" 16 m multispectral satellite data, is accurate relatively and could better meet the requirements of the crop dynamic monitoring business operational running.
\end{abstract}

Key words: remote sensing; "Gaofen-1" satellite; winter wheat; planting area; correction coefficient

Following the development of remote sensing technology, various types of remote sensing data were applied to monitor planting area of crops. There are several advantages of remote sensing technology, such as timeliness and objectivity, which could meet multi level requirements of agricultural. Di Wang et $\mathrm{al}^{[1]}$, based on the data of SPOT4, extracted the planting area of winter white for calculating the inter annual variation of area. Laigang Wang et $\mathrm{al}^{[2]}$, monitored winter wheat area in Henan with the free data of HJ-1satellite CCD. Lvyuan Hao et al $^{[3]}$, Used MODIS data to extract the planting area of Winter Wheat in the North China Plain in 2009. And the HJ-1 satellite classification data gained from multi temporal phase in the same year were used as the reference value to verify the results. Kebao Liu et $\mathrm{al}^{[4]}$, used high resolution remote sensing image RapidEye to extract crop planting area. At the same time calculated correction coefficient by the ground samples to correct area extraction results.

On one hand, in previous studies, the researchers used a variety of remote sensing data sources (such as RapidEye, SPOT, HJ-1 CCD, MODIS, etc.) on different scales to monitor the planting area of crops. Using low

The Author : Liu Yuechen (1983-) , male, engineer, member of Chinese Commission of Agricultural Engineering, the practice of land use and agricultural remote sensing. Key Laboratory of Cultivated Land Use, Ministry of Agriculture, P. R. China / Chinese Academy of Agricultural Engineering, MaiZidian street 41 , Chaoyang District, Beijing, 100125,China. Email: liuyuechen@agri.gov.cn 
resolution remote sensing images can effectively improve the time resolution and reduce the cost, but which would generate large number of mixed pixel to decrease the ability of spectrum identification to affect the accuracy of the crop planting area extraction. In contrast, using in high resolution remote sensing image extraction of crop acreage, to obtain more color, texture, shape and other characteristics of information, object recognition is higher, but affected by the revisit time length and single image coverage and other factors, the number and coverage of data acquisition were greatly restricted, and the cost of data was higher, and the applicability of the crop dynamic monitoring business operational running is not well. On the other hand, some researchers used ground samples to correct area extraction results had slightly insufficiency. Covering an area of ground sample is usually small. Correct interpretation results using a limited number of samples, couldn't meet the requirements to improve the overall accuracy.

China high-resolution earth observation system satellite 1 (Hereinafter referred to as "GF-1") set with blue, green, red and near infrared four bands, in terms of spatial resolution, revisit time length and single image coverage has comprehensive advantages. GF-1 data can very good solve rapid data acquisition, single image to cover a wider range, improve the object recognition, and other issues at the same time. The small size and low cost micro unmanned aerial vehicle information acquisition technology platforms (Hereinafter referred to as "micro-UAV") have been widely applied in agricultural field in recent years. It could offer a fast and flexible way to acquire data for crop management and monitoring, and is capable of rapidly provision of high resolution images. At the same time Micro-UAV will be able to collect a larger range of data, and the accuracy of data is similar as ground sampling data.

Based on the above, this study illustrate by a case of Jizhou in Hebei province, use GF-1 data to monitor the planting area of winter wheat, and then use the UAV data to modify the area extraction results to solve the problem of mutual restriction between precision and cost and provide scientific basis for the development of operational monitoring in a large scale.

\section{Study Area and Data}

\subsection{Research of regional}

Jizhou city is continental monsoon climate characteristics significantly, with four distinct seasons, rain and heat over the same period. Flat terrain and suitable soil, is benefiting to the cultivation of food crops. The major food crops include winter wheat and corn in Jizhou. The location map of Jizhou is shown in Figure 1. 


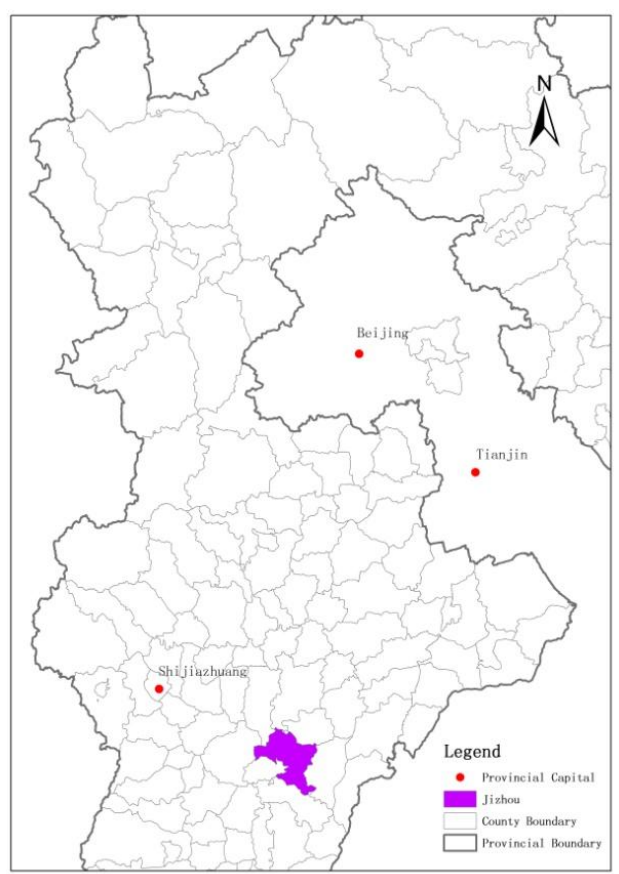

Fig.1 Location Map of Jizhou City

\subsection{Data Acquiring and Data Preprocessing}

\subsubsection{Remote Sensing Data Acquiring}

GF-1 is a satellite with 2-metre resolution CCD camera, and an 8-metre resolution multi-spectrum imager, and a 16-metre resolution wide-field multi-spectrum imager while covering an area of 800 kilometers. It means that GF-1 can observe the whole globe within 4 days. Winter wheat biomass was relatively stable during the winter, the spectral features presented on the satellite images are obviously, and less vegetation types in winter. So this study chose the fusion data of $2 \mathrm{~m}$ resolution and $8 \mathrm{~m}$ resolution of GF-1(Hereinafter referred to as " $\mathrm{GF}_{2 \mathrm{~m}}$ "), and chose GF-1 16 meter resolution data(Hereinafter referred to as "GF ${ }_{16 \mathrm{~m}}$ "). The two kinds of GF-1 data were in 2015. On the basis of visual pre judgment of crop planting in Jizhou city, arranged some ground sample area in the cultivated land uniformly, and then collected distribution information data of ground objects in the ground sample area by micro-UAV for correcting the extraction results of planting area of winter wheat. The remote sensing data acquisition is shown in Table 1.

Tab.1 Remote Sensing Data Acquisition

\begin{tabular}{ccccc}
\hline Data Type & $\begin{array}{c}\text { Resolution } \\
(\mathrm{m})\end{array}$ & $\begin{array}{c}\text { Image } \\
\text { Width } \\
\left(\mathrm{km}^{2}\right)\end{array}$ & $\begin{array}{c}\text { Number } \\
\text { Data }\end{array}$ & Data Temporal \\
\hline $\mathrm{GF}_{16 \mathrm{~m}}$ & 16 & 200 & 1 & 2014.12 .25 \\
$\mathrm{GF}_{2 \mathrm{~m}}$ & 2 & 40 & 4 & $2014.11 .18-2015.1 .2$ \\
Micro-UAV & 0.5 & $2 \sim 5$ & 5 & 2015.4 .20 \\
\hline
\end{tabular}

\subsubsection{Ground Survey Data Acquisition}

Acquired crops, leisure farmland, saplings and other key features of the interpretation signs information by GPS in the study area and investigated the situation of crops in the region. 


\subsubsection{Data Preprocess}

Geometric correction, projection conversion, image mosaic and cropping the data of $\mathrm{GF}_{2 \mathrm{~m}}, \mathrm{GF}_{16 \mathrm{~m}}$ and micro-UAV are carried. GF-1 data coverage is shown in Figure 2 and micro-UAV data distribution is shown in Figure 3.

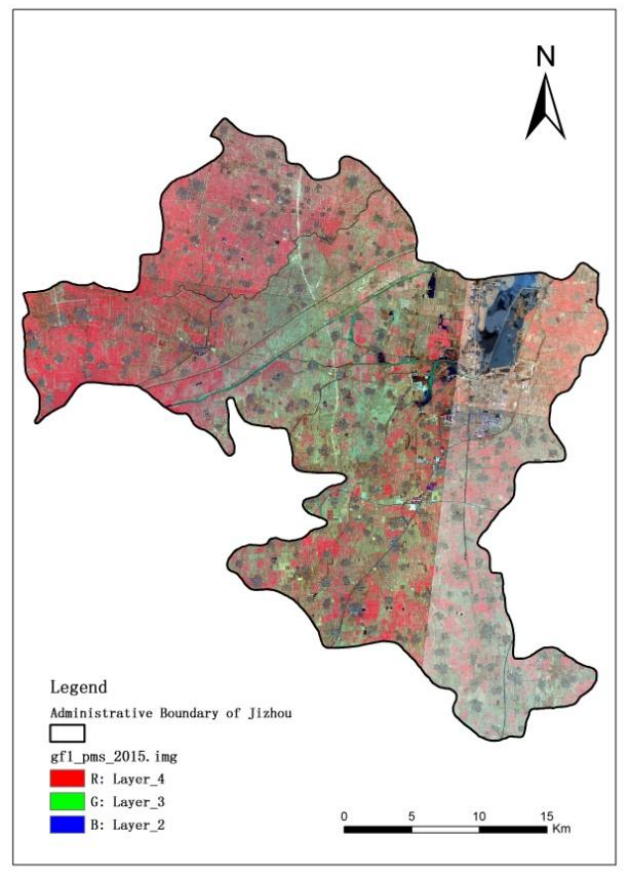

(a) $\mathrm{GF}_{2 \mathrm{~m}}$ Coverage of Jizhou City in 2015

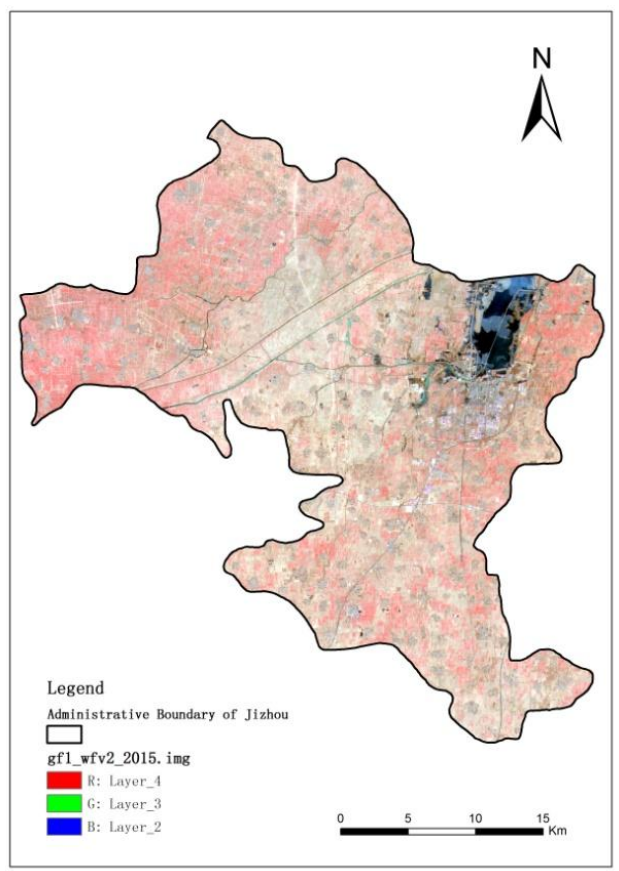

(b) $\mathrm{GF}_{16 \mathrm{~m}}$ Coverage of Jizhou City in 2015

Fig.2 GF-1 Data Coverage of Jizhou City 


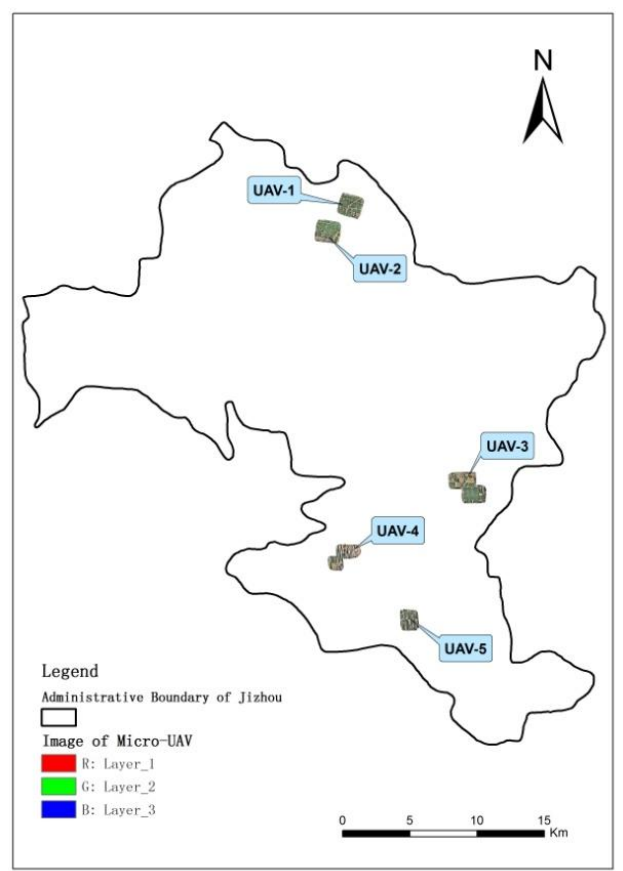

Fig.3 Micro-UAV Data Distribution

\section{Research Method}

Combining with the computer auto-classification and manual visual interpretation as a method and basing on the information came from ground investigation to extract the planting area of winter wheat from the $\mathrm{GF}_{16 \mathrm{~m}}$, $\mathrm{GF}_{2 \mathrm{~m}}$ and micro-UAV data of Jizhou city for 2015 years. Calculate the correction coefficient by the results of planting area of winter wheat gotten from $\mathrm{GF}_{16 \mathrm{~m}}$ and micro-UAV data. Correct the extraction result of planting area of winter wheat. Calculate accuracies of the results in $\mathrm{GF}_{2 \mathrm{~m}}$ and $\mathrm{GF}_{16 \mathrm{~m}}$, combining with the data of micro-UAV. Using $\mathrm{GF}_{2 \mathrm{~m}}$ data of winter wheat planting area extraction results to verify the accuracy of winter wheat planting area before and after the correction for evaluating the capability of the method combined with $\mathrm{GF}_{16 \mathrm{~m}}$ and micro-UAV data in operational running monitoring.

\subsection{The Establishment of Interpretation symbols}

Basing on the ground investigation and analyzing the satellite image, established the interpretation symbols database about the $\mathrm{GF}_{16 \mathrm{~m}}$ and micro-UAV data. On different data types, the color of the ground object is different. Such as in the $\mathrm{GF}_{16 \mathrm{~m}}$ image data, winter wheat show orange and dark red and mixed with light gray and slightly rough texture; Leisure cultivated land has pale orange yellow and sky blue; woodland showed reddish brown and black purple. In the $\mathrm{GF}_{2 \mathrm{~m}}$ image data, Winter wheat were presented in red and pink, mixed with dark red; leisure cultivated showed gray blue and gray green; woodland showed strip sky blue and red and pink and purple and pink and pink. In the micro-UAV image data, winter wheat is red; leisure cultivated presents gray blue, mixed with white stripes; woodland showed blue black, gray with blue stripes. Interpretation symbols of key features of Jizhou city is shown in Table 2. 


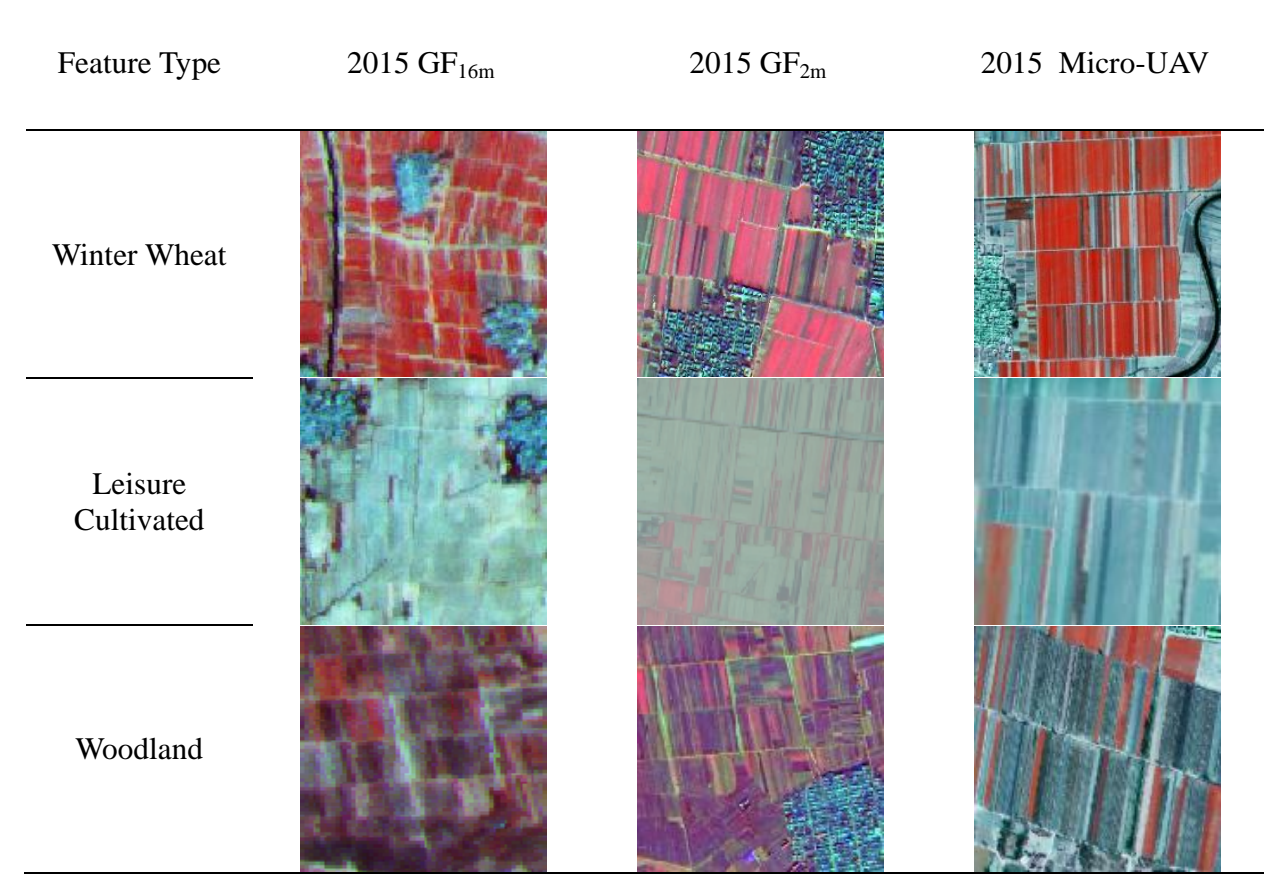

\subsection{Correction Coefficient}

Using the results of planting area of winter wheat got from micro-UAV and $\mathrm{GF}_{16 \mathrm{~m}}$ data, calculate the correcting factor. The result of planting area got from $\mathrm{GF}_{16 \mathrm{~m}}$ data should intercept the same region to each micro-UAV data's coverage.

Correction Coefficient $=\mathrm{R}-\mathrm{GF}_{16 \mathrm{~m}} / \mathrm{R}-\mathrm{UAV}$......Formula (1)

$\mathrm{R}-\mathrm{GF}_{16 \mathrm{~m}}$ : The result of planting area of winter wheat got from $\mathrm{GF}_{16 \mathrm{~m}}$ data with the same scope as micro-UAV data's coverage.

R-UAV : The result of planting area of winter wheat got from Micro-UAV.

The correction coefficient is more than 1 value, indicates that there are errors that interpretation planting area of winter wheat is too much in the data of $\mathrm{GF}_{16 \mathrm{~m}}$. The greater the correction coefficient is, the lower the accuracy of interpretation.

The correction coefficient is less than 1 value, indicates that there are errors that interpretation planting area of winter wheat is missed. The more close to the 0 value of the correction coefficient, the lower the accuracy of interpretation.

The more close to the 1 value of the correction coefficient, indicates that the accuracy of the interpretation planting area of winter wheat is higher.

\section{The Planting Area Monitoring Results and Analysis}

\subsection{Calculation of Correction Coefficient of GF16m Data}

According to the formula (1), combined with data of Micro-UAV and the data of $\mathrm{GF}_{16 \mathrm{~m}}$ and $\mathrm{GF}_{2 \mathrm{~m}}$, corresponding to the location of sample area of each data of Micro-UAV, to calculate the correction coefficient. Then calculate the average value of correction coefficient of every sample's, as the correction coefficient final value of extraction result of planting area of 
winter wheat in Jizhou of the data of $\mathrm{GF}_{16 \mathrm{~m}}$. And calculate the average value of accuracy of every sample's separately, as the accuracy final value of extraction result of planting area of winter wheat in Jizhou of the data of $\mathrm{GF}_{16 \mathrm{~m}}$ and $\mathrm{GF}_{2 \mathrm{~m}}$. Table 3 shows that the correction coefficient of final value $\mathrm{GF}_{16 \mathrm{~m}}$ is 1.2105 . The accuracies of the two kinds of GF-1 data $\left(\mathrm{GF}_{2 \mathrm{~m}}\right.$ and $\mathrm{GF}_{16 \mathrm{~m}}$ )are $96.62 \%$ and $82.73 \%$. Figure 4 shows a part of the same area of the interception of UAV data and GF-1 data extraction results. As can be seen from the figure 4 and the table 3 , the extraction results of winter wheat planting area of the $\mathrm{GF}_{2 \mathrm{~m}}$ data are close to the results of the UAV data. Therefore, the study uses the result of $\mathrm{GF}_{2 \mathrm{~m}}$ data as the true value of planting area of winter wheat in Jizhou.

Tab.3 Accuracy Verification and Correction Coefficient Calculation

\begin{tabular}{|c|c|c|c|c|c|c|c|}
\hline \multirow{2}{*}{$\begin{array}{c}\text { Data } \\
\text { Number }\end{array}$} & \multirow{2}{*}{$\begin{array}{c}\text { The } \\
\text { Coverage } \\
\text { of Each } \\
\text { Data of } \\
\text { Micro-UAV } \\
\text { ( ha ) }\end{array}$} & \multirow{2}{*}{$\begin{array}{c}\text { The } \\
\text { Planting } \\
\text { Area of } \\
\text { Winter } \\
\text { Wheat in } \\
\text { Micro-UAV } \\
\text { ( ha ) }\end{array}$} & \multirow{2}{*}{$\begin{array}{c}\text { The } \\
\text { Planting } \\
\text { Area of } \\
\text { Winter } \\
\text { Wheat } \\
\text { in } \mathrm{GF}_{2 \mathrm{~m}} \\
\text { ( ha ) }\end{array}$} & \multirow{2}{*}{$\begin{array}{c}\text { The } \\
\text { Planting } \\
\text { Area of } \\
\text { Winter } \\
\text { Wheat } \\
\text { in } \\
\mathrm{GF}_{16 \mathrm{~m}} \\
\text { ( ha ) }\end{array}$} & \multicolumn{2}{|c|}{$\begin{array}{c}\text { The } \\
\text { Interpretation } \\
\text { Accuracy }\end{array}$} & \multirow{2}{*}{$\begin{array}{c}\text { The } \\
\text { Correction } \\
\text { Coefficient } \\
\text { of } \mathrm{GF}_{16 \mathrm{~m}}\end{array}$} \\
\hline & & & & & $\begin{array}{l}\mathrm{GF}_{2 \mathrm{~m}} \\
(\%)\end{array}$ & $\begin{array}{c}\mathrm{GF}_{16 \mathrm{~m}} \\
(\%)\end{array}$ & \\
\hline UAV-1 & 283.3 & 200.0 & 204.9 & 233.1 & 97.60 & 85.80 & 1.1655 \\
\hline UAV-2 & 294.9 & 164.4 & 170.3 & 197.7 & 96.53 & 83.15 & 1.2026 \\
\hline UAV-3 & 491.7 & 259.1 & 268.9 & 314.6 & 96.35 & 82.36 & 1.2142 \\
\hline UAV-4 & 294.3 & 100.4 & 104.7 & 130.5 & 95.89 & 76.93 & 1.2998 \\
\hline UAV-5 & 199.3 & 124.3 & 128.5 & 145.5 & 96.73 & 85.42 & 1.1706 \\
\hline UAV-1 & 283.3 & 200.0 & 204.9 & 233.1 & 97.60 & 85.80 & 1.1655 \\
\hline \multicolumn{5}{|c|}{ The Final Value } & 96.62 & 82.73 & 1.2105 \\
\hline
\end{tabular}

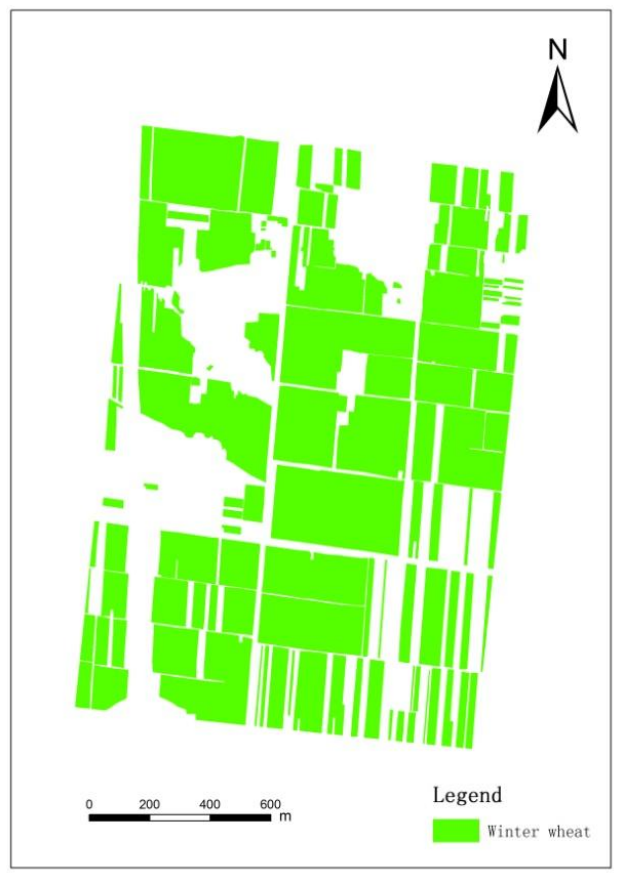

(a) Micro-UAV data interpretation effect 


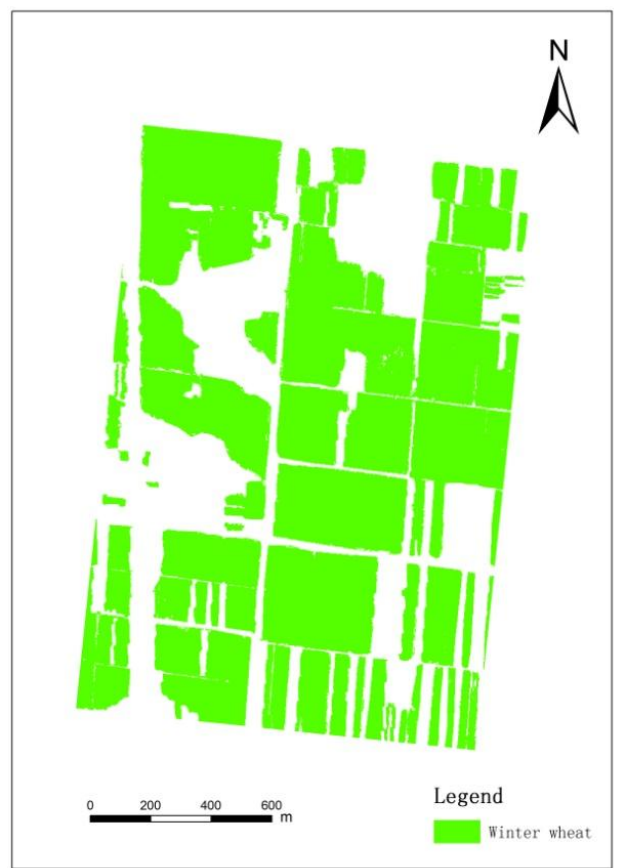

(b) $\mathrm{GF}_{2 \mathrm{~m}}$ data interpretation effect

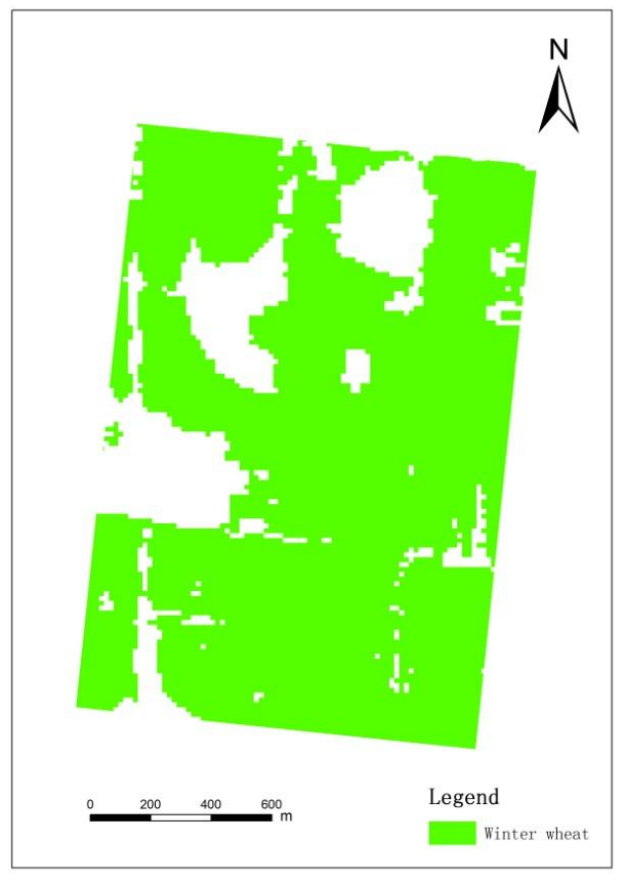

(c) $\mathrm{GF}_{16 \mathrm{~m}}$ data interpretation effect

Fig. 4 Comparison of GF-1 Data and UAV Data in Winter Wheat Interpretation

\subsection{Analysis of Monitoring Results of Planting Area}

Table 4 shows that the uncorrected extraction result of planting area of winter wheat is 34804.5 ha, and the corrected extraction result of planting area of winter wheat is 27478.2 ha, two results both came from the data of $\mathrm{GF}_{16 \mathrm{~m}}$ in Jizhou. The result of planting area of winter wheat, extracted by the data of $\mathrm{GF}_{2 \mathrm{~m}}$ in Jizhou is 29329.3 ha. The results show that the result of corrected extraction area of $\mathrm{GF}_{16 \mathrm{~m}}$ data is closing to the result of $\mathrm{GF}_{2 \mathrm{~m}}$. 
Tab. 4 Comparison of Winter Wheat Planting Area

\begin{tabular}{|c|c|c|c|c|}
\hline $\begin{array}{c}\text { Uncorrected } \\
\text { Planting Area } \\
\text { of } \mathrm{GF}_{16 \mathrm{~m}} \\
\text { ( ha })\end{array}$ & $\begin{array}{c}\text { Correction } \\
\text { Coefficient }\end{array}$ & $\begin{array}{c}\text { Corrected } \\
\text { Planting Area } \\
\text { of } \mathrm{GF}_{16 \mathrm{~m}} \\
(\text { ha })\end{array}$ & $\begin{array}{c}\text { Planting } \\
\text { Area of } \\
\mathrm{GF}_{2 \mathrm{~m}} \\
(\text { ha })\end{array}$ & $\begin{array}{c}\text { Accuracy of } \\
\text { Extraction } \\
\text { Result of } \mathrm{GF}_{16 \mathrm{~m}} \\
(\%)\end{array}$ \\
\hline 34804.5 & 1.2105 & 27478.2 & 29329.3 & 93.69 \\
\hline
\end{tabular}

\section{Conclusion}

Comparing with the results of planting area extraction of winter wheat in the data of $\mathrm{GF}_{16 \mathrm{~m}}$ and $\mathrm{GF}_{2 \mathrm{~m}}$, it can be found that the corrected extraction result of planting area of winter wheat, from the data of $\mathrm{GF}_{16 \mathrm{~m}}$, is accurate relatively. At the same time, comparing to the data of $\mathrm{GF}_{2 \mathrm{~m}}$, the data of $\mathrm{GF}_{16 \mathrm{~m}}$ has shorter revisit period and greater coverage. $\mathrm{GF}_{16 \mathrm{~m}}$ can be better to avoid the problem of less data obtention, in a limited period of crop growth, caused by the reasons of weather. It could better meet the requirements of the crop dynamic monitoring business operational running.

\section{Reference}

[1] Wang D, Zhou Q B, Liu J. Studies on experiment of optimizing design of space sampling frame and sampling basic elements of crop areas. Journal of China Agricultural Resources and Regional Planning, 2008,29 (4):9 15.

[2] Wang L G, Zheng G Q, Chen H L, Zou C H, Liu Z Y, Cheng Y Z. Monitoring the change of global winter wheat planting area in Henan province based on HJ-CCD image. Journal of China Agricultural Resources and Regional Planning, 2001,32 (2) :58 62.

[3] Hao L Y, Sun R, Xie D H, Tang Y, Wang Y. Planting area extraction of winter wheat in north China plain based on optimized N-FINDR algorithm. Transactions of Chinese Society of Agricultural Engineering, 2013,29(15): $153 \sim 161$.

[4] Liu K B, Liu S B, lu Z J, Song Q, Liu Y X, Zhang D M, Wu W B. Extraction on cropping structure based on high spatial resolution remote sensing data. Journal of China Agricultural Resources and Regional Planning, 2014,35

(1) $: 21 \sim 26$. 